\title{
Gênero e poder. Leituras transculturais - quando o sertão é mar, mas o olhar estranha, encalha em recifes"
}

\author{
Mary Garcia Castro**
}

\section{Bastidores do texto e o conceito de transculturação}

Este artigo abrevia debate mais desenvolvido em outro espaço (ver nota 1). Estimula algo comentar sobre a diversidade do debate feminista sobre gênero e poder no Brasil, nos anos 90, os riscos dos relatos sobre rota de idéias viajantes, partindo da tese de que tais viagens fazem parte de uma mais ampla circulação, que envolve certo tipo de globalização de vocabulário $e$ a localização de significados - processo que pode assumir diferentes formas.

Viagens e desembarques de idéias são comumente representados por simplificações, registrando-se, por exemplo, a contribuição de um autor ou uma escola de pensamento, como o representante do feminismo brasileiro, em leituras "estrangeiras" estrangeiras não necessariamente em termos do outro, o de fora, mas pelo olhar estranho, incapaz de dar conta do heterogêneo, da

\footnotetext{
* Recebido para publicação em outubro de 2001. Texto baseado em artigo apresentado na "Pré-conferência de gênero: travessia feminista e alianças transnacionais: encontros e desencontros entre o pensamento e prática feministas" - Seção de Gênero e Estudos Feministas - Associação de Estudos Latino Americanos (LASA), em 5 de setembro de 2001, Washington D.C., EE.UU.

** Pesquisadora da UNESCO-Representação no Brasil; Pesquisadora Associada da Universidade de Campinas - Centro de Estudos de Migrações Internacionais (Programa PRONEX-CNPq); Professora Aposentada da Universidade Federal da Bahia-Brasil.
} 
Gênero e poder. Leituras transculturais

diversidade de chegadas e re-vestidas das idéias, e sem o necessário cuidado com as próprias projeções (leituras estrangeiras sobre viagens e múltiplas chegadas das idéias são comuns também entre autores "nativos"). Tal estranhamento também pode ocorrer nos relatos articulações entre teoria e práticas, comumente procedendo-se a leituras ligeiras.

O texto está organizado considerando primeiro, de forma abreviada, algo sobre a produção feminista de corte acadêmico no Brasil nos anos 90, quanto ao conceito de gênero em suas relações com o conceito de poder. A intenção é ilustrar, mas não cobrir, a complexidade e riqueza do campo no Brasil.

Segue-se, ilustração de uma leitura transcultural da idéia de "empoderamento" de gênero por mulheres de organizações de base Comunitária (OBCs) - item básico na Conferência das Nações Unidas sobre Mulheres (Beijing, 1995), que tem sido usado $e$ abusado por agências internacionais e feministas. Recorro à pesquisa desenvolvida para a UNESCO com mulheres naquelas organizações em diferentes estados no Brasil. ${ }^{1}$

O objetivo, com tais exercícios, é questionar a universalidade, para o Brasil, da idéia apresentada por Thayer, quando em pesquisa sobre o uso do conceito de gênero no MMTR (Movimento das Mulheres Trabalhadoras Rurais) em Pernambuco - movimento fundado em 1982, segundo Thayer. ${ }^{2}$ A autora sugere que o MMTR procederia a um uso instrumental do importado conceito de "empoderamento" para poder introduzir agenda feminista em uma organização política mista (i.e, composta por homens $e$ mulheres) $e$ agradar agências internacionais financiadoras, interessadas na difusão do conceito. Questiono a possibilidade de generalização dessa interpretação, advogando que esses são alguns entre outros usos dados a "empoderamento" por organizações de base.

1 ABRAMOVAY, Miriam e CASTRO, Mary Garcia. Engendrando um novo feminismo: mulheres líderes de base. Brasilia, UNESCO, 1998.

2 THAYER, Millie. Feminismo transnacional: re-lendo Joan Scott no Sertão. Revista de Estudos Feministas, vol. 9, n 1, 2001, pp.103-130. 
Questiono também a idéia, também sugerida no artigo de Thayer, de que o conceito de gênero no meio acadêmico brasileiro, assim como na militância de $\mathrm{OBCs}$, teria sido introduzido pela tradução do artigo "Gênero: Uma Categoria Útil da Análise Histórica" de Joan Scott. ${ }^{3}$ Thayer defende que o debate sobre gênero e poder tenha chegado ao MMTR por indução da organização feminista SOS, o que a meu juízo não dá conta da riqueza do trabalho do SOS, que nos seus 20 anos vem se destacando pelas relações de simetria com os movimentos de base e por uma ampla produção sobre gênero. ${ }^{4}$

Defendo que feministas marxistas brasileiras e outras têm apresentado críticas aos trabalhos de Scott, como por exemplo Saffioti e Machado ${ }^{5}$, e que, por outro lado, diferentes autores têm influenciado ativistas em $\mathrm{OBCs}$ no que toca a relação gênero $e$ poder.

Por outro lado, baseada em ampla pesquisa com OBCs de corte feminista no Brasil ${ }^{6}$, sustento que tais organizações têm leituras próprias, transculturais sobre gênero e poder, e diferentes

3 ScotT, Joan W. Gender: A Useful Category of Historical Analysis. American Historical Review, vol. 91, no 5, 1986; Também em Gender and the Politics of History. New York, Columbia University Press, 1988, pp.28-50. Versão em português: Gênero: uma categoria útil de análise histórica. Educação e Realidade, Porto Alegre, UFRGS, 1990. (Thayer cita tradução de 1991 feita pelo SOS Corpo.)

4 Entre outras publicações mais relacionadas com o debate conceitual sobre gênero, publicadas pelo SOS Corpo de Recife, cito: CORRÊA, Sonia. Gênero: reflexóes conceituais, pedagógicas e estratégicas. 1994; GOUVEIA, Taciana e CAmurÇA, Silvia. O que é gênero. 1997; Portella, Ana Paula e GouveiA, Taciana. Idéias e dinâmicas para trabalhar com gênero. 1999; OxfAM. Manual de formação em gênero da Oxfam. 2000; DE BARBIERI, Terezita. Sobre a categoria gênero: uma introdução teórico-metodológica. 1994.

5 SAFFIOTI, Heleieth. O estatuto teórico da violência de gênero. In: SANTOS, José Vicente Tavares dos. Violência em tempo de globalização. São Paulo, Hucitec, 1999; e MACHADO [1990] apud ARAÚJO, Clara. Marxismo, feminismo e o enfoque de gênero. Crítica Marxista, no 11, pp.65-70.

6 Abramovay, M. e CASTRO, M. G. Engendrando um novo feminismo... Op. cit. 
Gênero e poder. Leituras transculturais

segundo organização e projeto político e um pouco da riqueza de tal diversidade é no artigo retratada.

Autores feministas na academia brasileira vêm usando o conceito de gênero anterior à tradução de Scott, com diferentes abordagens. Por outro lado, $\mathrm{OBCs} e$ entidades que viriam conjugando classe e gênero, como as de orientação feministas em sindicatos, não reproduzem passivamente a produção feminista acadêmica $^{7}$, mas são vários os textos do repertório de leituras das OBCs, como são diversos os tipos de contactos com escritos e práticas no exterior. Em síntese, considerar que o MMTR ilustra uma "re-leitura de Joan Scott no sertão" (título do artigo de Thayer) e que tal exercício significaria um "feminismo transnacional" (também parte do título do artigo citado) é em si uma viagem que não dá conta do observado, ou de que o sertão há muito é mar.

Também critico a tese de que no feminismo brasileiro haveria necessariamente uma separação entre o escrito na academia e o recorrido por práticas de entidades de movimentos populares $^{8}$, considerando que tal trânsito é mais complexo e requer análises de tipos de feminismos, pois, de fato, alguns não encontram eco em OBCs, enquanto outros tipos são tidos como interlocutores.

O projeto político crítico de feministas que conjugam classe e gênero, ou um feminismo de bases classistas, vem dando impulso peculiar a interpretações transculturais do conceito de gênero em movimentos sociais. A tendência é combinar gênero, classe e, às vezes, raça. Não apenas considerando múltiplas discriminações, mas, também, a linguagem da rebelião.

7 o que também bem demonstra THAYER, M. Feminismo transnacional... Op. cit.

8 Tese desenvolvida em SoARes, Vera; Alcantara Costa, Ana Alice; Buarque, Cristina; DOURADo DorA, Denise; e SANT'ANNA, Wania. Brazilian Feminism and Women's Movements: A Two-Way Street. In: BASU, Amrita. The Challenge of Local Feminisms. Women's Movement in Global Perspective. San Francisco, Westview Press, 1995. (Original em inglês.) 
Recorro ao conceito de transculturação em um sentido específico. Transculturação se faz importante para retraçar a tradução, a viagem dos conceitos e como esses desembarcam $e$ são re-adotados, ou seja, reformatados a partir de experiências e interesses locais. ${ }^{9}$

O conceito de transculturação foi inaugurado pelo antropólogo cubano Fernando Ortiz (em 1940-1995) e usado por Pratt

para substituir os conceitos de desculturação e a-culturação que descreveriam a transferência de culturas de uma forma reducionista, como se adscrito a reproduzir os interesses da metrópole. ${ }^{10}$

O conceito de transculturação chama a atenção para formas criativas que grupos "subordinados ou grupos marginais selecionam $e$ inventam, a partir de materiais transmitidos a eles por uma cultura dominante ou metropolitana". ${ }^{11}$

Uma leitura transcultural de categorias feministas do Norte feita por feministas do Sul pode seguir ou rejeitar diferentes mapeamentos. ${ }^{12}$

9 Tese também desenvolvida por THAYER, Millie. Traveling Feminisms: From Embodied Women to Gendered Citizenship. Apresentado no Congresso da LASA, Chicago, 1998 [NE: Traduzido em Cadernos Pagu (12), Núcleo de Estudos de Gênero - Pagu, Unicamp, 1999, pp.203-249]; e Feminismo transnacional... Op. cit.

${ }^{10}$ PRATT, Mary Louise. Imperial Eyes. Travel Writing and Transculturation. New York, Routledge, 1992, p.228.

${ }^{11}$ ID, IB., p.6.

${ }^{12}$ De acordo com Coronil, sobre o trabalho de Fernando Ortiz, - quem inaugurou o conceito de transculturação nos anos 1940: "Ortiz celebra a automodelagem dessas periferias (periferias dependentes, cuja elaboração é entalhada por centros soberanos). Destaca os contrapontos através dos quais as pessoas tornam margens em centros e de fragmentadas histórias chegam a identidades fluidas e coerentes". Não há uma "aculturação", ou seja, uma transição restrita a um valor de representação dominante. Tal essencialismo é questionado, então, poder é uma concepção relativa. CoRONIL. Introdução. In: 
Gênero e poder. Leituras transculturais

\section{Pensamento feminista no Brasil sobre gênero e poder - alguns debates dos anos 90}

Algumas autoras passam uma imagem do feminismo no Brasil, em textos publicados no exterior, de que nos anos 90, "não haveria uma articulação entre teoria e prática ou entre ação feminista e produção acadêmica". ${ }^{13}$ Refuto tal generalização, considerando que o dialogo entre feministas na academia e em organizações de base comunitária ou de classe, como sindicatos $e$ de distintos movimentos, como o movimento negro, assim como as múltiplas inserções é uma característica histórica da produção feminista brasileira. Também considero que não há apenas uma forma de articulação, considerando a diversidade de trajetórias pessoais de feministas na academia, assim como a diversidade no mundo de organizações não governamentais (ONGs) e de entidades do movimento feminista em termos de projetos políticos e ideológicos. Também entendo que:

1. O feminismo engendrado na academia ou de corte intelectual (os quais não se confundem sempre) é um tipo de movimento social, já que pode contribuir para a "instabilidade de categorias"14 ou a desconstrução de paradigmas tradicionais, concepções dualistas, suposições genéricas que deixam de levar em conta a complexidade da vida cotidiana e o "capital social"15

ORTIZ, Fernando. Cuban Counterpoint. Tobacco and Sugar. Durham, Duke University, 1995. Ortiz adverte que aculturação: "implica na aquisição de uma cultura em um processo unidirecional. Por outro lado, transculturação sugere um processo em que se dão duas fases: a perda ou o desarraigamento de uma cultura (deculturation) e a criação de uma nova cultura (neoculturation). Ortiz considera, assim, tanto a destruição de culturas, como a criatividade das articulações culturais".

${ }^{13}$ SOARES, V. et alii. Brazilian Feminism and Women's Movements... Op.cit.

${ }^{14}$ HARDING, Sandra. The Instability of the Analytical Categories of Feminist Theory. Signs - A Journal of Women in Culture and Society, vol. 11, $\mathrm{n}^{\circ} 4$, Chicago, 1986, pp.645-664.

${ }^{15}$ BouRdiEu, Pierre. A dominação masculina. São Paulo, Bertrand Brasil, 1999. 
das mulheres. O feminismo territorializado na academia contribuiu para tornar visíveis certos processos não considerados no pensamento científico dominante, tais como: o valor de produção do trabalho doméstico; o conteúdo político das emoções; e a interação entre o público e o privado. O feminismo na academia brasileira, em particular, contribuiu para debates sobre: diferenças e diversidades; a lógica das hierarquias e do poder, além das macro estruturas; o gênero como constituinte de uma linguagem, baseado em relações sociais; a complexidade da alquimia de identidades como classe, raça e gênero; o valor da subjetividade nas rebeliões políticas públicas; e o valor do simbólico. Neste sentido, como o movimento da "nova história", que recorreria às histórias ocultas dos marginalizados, das pessoas comuns ${ }^{16}$, questionaria as formas tradicionais de conceber quem eram os sujeitos da história. O pensamento feminista viria transformando um velho mundo orientado por categorias masculinas, ou seja, o mundo acadêmico ${ }^{17}$;

2. No Brasil, algumas de nós, que fizemos parte da geração feminista histórica dos anos 60-70, viemos de uma história de luta contra a ditadura. Nós participamos da construção do sindicalismo social, da fundação do Partido dos Trabalhadores-PT e de outras instituições orientadas por postura de esquerda. Algumas de nós continuamos em partidos políticos com tal alinhamento ou mantemos contatos com movimentos sociais e OBCs. Outras feministas daquela geração fazem parte hoje da maquinaria estatal, algumas são membros de partidos da situação e outras chefiam ONGs dos mais diversos formatos e cores políticas. Outras

${ }^{16}$ PeRrot, Michelle. Femmes publiques. Paris, Les Editions Textuels, 1997.

${ }^{17}$ Para um estudo menos abreviado sobre as contribuições do feminismo brasileiro para o conhecimento acadêmico ver, entre outros, BANDEIRA, Lourdes e SIQUEIRA, Deise. A perspectiva feminista no pensamento moderno e contemporâneo. Sociedade e Estado, vol XII, no 2, Julho/dezembro 1997, pp.263-284; e GolDBERG-SALINAS, Anette. Estratégias das mulheres nos movimentos e interesse dos homens no poder. Sociedade e Estado, $\mathrm{n}^{\circ} 2$, Julho/dezembro 1997, pp.357-382. 
Gênero e poder. Leituras transculturais

conjugam tais localizações, ou não, com carreiras na academia ou em outras áreas profissionais.

Quanto ao alinhamento teórico-político também o quadro não é monofônico, ao contrário. Por exemplo, só citando duas entre várias correntes de pensamento entrelaçadas a feminismos: vem crescendo a ênfase na linguagem, no discurso $e$ nas referências simbólicas na produção feminista acadêmica, comumente com um acento pós-estruturalista e até pós-feminista, mas, por outro lado, um feminismo marxista renovado se faz também presente, disputando significados, reacendendo análises sobre cultura, poder e sistemas de discriminação e linguagens de rebelião. ${ }^{18}$

A diversidade entre os feminismos brasileiros e entre feministas, mais do que uma única tendência, é enfatizada por distintos autores que implicitamente refutam a simplificação entre formas de interação entre teoria e prática no feminismo brasileiro ${ }^{19}$;

3. Também os movimentos de mulheres e feministas de tipo OBCs são muito diferentes hoje e empregam diferentes tipos de meios de comunicação. Entre organizações de bases, no campo e na cidade, e em sindicatos, debates sobre conceitos e tópicos

\footnotetext{
${ }^{18}$ Sobre o uso do conceito de gênero com um enfoque marxista, ver, entre outros, GifFIN, Karen. Nosso corpo nos pertence: a dialética do biológico e do social. Cadernos de Saúde Pública, 7(2), 1991, pp.190-200; e Poder e prazer: considerações sobre o gênero e a sexualidade feminina. In: RiBEIRO, Marcos. (org.) O pensar e o prazer. São Paulo, Editora Gente/Cores, 1999; SAFFIOTI, Heleieth. Quem tem medo dos esquemas patriarcais de pensamento; BENOIT, Lelita Oliveira. Feminismo, gênero e revolução; QUARTIM DE MORAES, Maria Lygia. Marxismo e feminismo: afinidades e diferenças; e CASTRO, Mary Garcia. Marxismo, feminismos e feminismo marxista. Mais que um gênero em tempos Neoliberais. Todos os textos estão em Critica Marxista, no 11, 2000; ARAÚJO, Clara. Marxismo, feminismo e o enfoque de gênero. Op.cit.

${ }^{19}$ CASTRO, Mary Garcia. Engendrando poderes em tempos neo-liberais. Feminimos e feminismos, reflexões à esquerda; e MENICUCCI DE OLIVEIRA, Eleonora. A prática feminista e o gênero na construção do conhecimento. Ambos em Sociedade e Estado, vol XII, n 2, julho-dezembro de 1997.
} 
desenvolvidos a nível acadêmico, não só descobrem reapropriações criativas, únicas, mas algumas vezes, devido às dinâmicas dos movimentos sociais, na prática, conceitos ou perspectivas são transformados, realimentando pesquisas acadêmicas. O Estado, o trabalho $e$ as relações homem-mulher são revisados quando o conceito de gênero é usado e uma "dialética de trânsito entre o biológico e o social" está presente no discurso de alguns movimentos sociais de mulheres. ${ }^{20}$

A agenda de algumas dessas organizações vai além do enfoque funcionalista sobre gênero como uma posição ou uma categoria de uma linguagem do direito, advogando um papel, um lugar, uma negação de uma identidade cultural ou a busca de outra identidade.

\section{O debate sobre gênero e poder no Brasil: viagens e traduções}

Diferentemente dos estudos feministas franceses, o conceito de gênero no Brasil, nos anos 80, não encontrou grande resistência. Ao contrário, teve uma aceitação imediata, sem maiores discussões, embora tenha havido algumas vozes de oposição na comunidade feminista acadêmica. Hoje, após o uso e o abuso do conceito, especialmente pelas agências de desenvolvimento, algumas feministas têm chamado a atenção para a necessidade de ser mais restrita a diferenciação entre mulher, gênero e perspectivas feministas e, também, para o debate, no sentido de evitar identidades fixas e sua restrição a dimensões da vida, como sugerem os manuais sobre gênero. ${ }^{21}$

De qualquer modo, há alguns vazios entre a intenção teórica e o uso empírico do conceito, observado por Heilborn. Algumas

${ }^{20}$ GIFFIN, K. Nosso corpo nos pertence... Op. cit.; e Poder e prazer: considerações sobre o gênero... Op. cit.

${ }^{21}$ CASTRO, M. G. Engendrando poderes em tempos neo liberais... Op. cit.; e SAFFIOTI, H. O estatuto teórico da violência de gênero. Op. cit. 
Gênero e poder. Leituras transculturais

feministas envolvidas no debate teórico, sob a influência francesa, põem mais ênfase sobre as diferenças. ${ }^{22}$ Heilborn, por exemplo, defende que o termo gênero pode indicar relações de oposição, desde que o conceito empregue uma "forma elementar de diversidade". Outros autores enfatizam as relações sociais de poder. ${ }^{23}$ Para muitas, o conceito foi útil ao permitir enfocar as relações sociais de poder e o processo de construção da subordinação nas relações entre homens e mulheres, assim como entre mulheres e homens com o aparato do Estado. Para outras, como mencionado, é uma forma de abordagem sobre diversidades e diferenças, e para algumas autoras, é uma forma de tratar com sistemas múltiplos de desigualdades e dominação, nos níveis simbólico e material.

Gayle Rubin ${ }^{24}$ foi uma referência básica e um texto do qual decolaram polêmicas sobre o conceito de gênero no começo dos anos 90, no Brasil. Para algumas antropólogas, com orientações estruturalistas ${ }^{25}$, outro problema no uso da abordagem de gênero por feministas marxistas, do texto de Rubin ${ }^{26}$, foi também o viés sociológico que enfatizaria as relações sociais em termos de relações de poder. Aquelas autoras também acusaram as feministas marxistas de adotarem a "utopia" de Rubin em favor de uma sociedade sem gêneros. De acordo com aquelas antropólogas, gênero, como um princípio de diferença, seria pedra

22 OlvEIRA apud MACHADO, Lia Zanotta. "Feminismo, academia e Interdisciplinaridade; e HEILBORN, Maria Luíza. Fazendo gênero? A antropologia da mulher no Brasil. Ambos em Oliveira Costa, Albertina e BRUSCHINI, Cristina. Uma questão de gênero. Rio de Janeiro, Rosa dos Tempos, 1992.

${ }^{23}$ Por exemplo, CASTRO, Mary e LAVINAS, Lena. Do feminino ao gênero: a construção de um objeto. In: OliveIrA COSTA, A. de e Bruschini, C. Uma questão de gênero. Op. cit.

${ }^{24}$ Rubin, Gayle. The Traffic in Women. In: ReITER, Reyna. (ed.) Toward an Anthropology of Women. New York, Monthly Review Press, 1975, pp.157-210.

${ }^{25}$ MACHADO, L. Z. Feminismo, academia e interdisciplinaridade... Op. cit.; e HeILBORN, M. L. Fazendo gênero? A antropologia da mulher no Brasil... Op. cit.

${ }^{26}$ CASTRO, M. e LAVINAS, L. Do feminino ao gênero... Op.cit. 
Mary Garcia Castro

fundamental de debates contemporâneos para a metamorfose de subordinações, mas não poderia ser abolido como constituinte social.

Outra antropóloga, mais relacionada ao pós-estruturalismo $e$ baseando-se em Lacan, discute a tensão entre universalismo $e$ relativismo em estudos antropológicos feministas, assim como o dualismo sugerido pelas estruturalistas, como Heilborn. De acordo com Segato, gênero se refere, ao mesmo tempo, à construção histórico-social, à hierarquia simbólica universal $e$ às estruturas de subordinação. ${ }^{27}$

Uma outra perspectiva distinta sobre gênero é apresentada por Saffioti, que defende uma abordagem materialista histórica. Saffioti também apresenta uma extensa crítica ao trabalho sobre gênero e poder de Joan Scott. Ela observa que gênero, classe e raça entrelaçam-se na sociedade brasileira e que, a cada momento, uma dessas categorias é mais estratégica para mobilização visando mudança social. Saffioti argumenta que gênero não é apenas uma "categoria de análise", como entendida por leitores de Scott no Brasil, mas, como classe e raça, gênero é uma "categoria histórica". De acordo com Saffioti, um dos problemas no debate de Scott sobre gênero é o perigo do relativismo, uma vez que na abordagem dessa autora nenhum "limite estrutural é estabelecido". ${ }^{28}$

Leitura crítica do trabalho de Scott foi também desenvolvida por Machado, afirmando que gênero é um ponto - mas não o

${ }^{27}$ Segato assim resume seu artigo: "O artigo endossa uma visão de gênero como estrutura. Assim, a hierarquia do gênero pertence ao domínio do simbólico $e$ reside em algum lugar da realidade observável com a qual o etnógrafo trabalha. O gênero estrutura a realidade, imprimindo nela a organização de uma cena originária e transportando-a, usualmente, para os termos das relações familiares. Dessa perspectiva, a autora somente vislumbra uma saída do círculo hierárquico de poder e sujeição do desejo: revelar a dinâmica usual - embora geralmente mascarada - de androginia como circulação, que é parte ordinária da experiência dos sujeitos sociais". SEGATO, Rita Laura. Os percursos do gênero... Op. cit., p.235.

${ }^{28}$ SAFFIOTI, H. O estatuto teórico da violência de gênero. Op. cit. 
Gênero e poder. Leituras transculturais

único - de referência social. Machado mencionaria um "imperialismo conceitual" no uso de gênero por algumas feministas no Brasil, que seguem a orientação de Scott. ${ }^{29}$

Saffioti também discute a centralidade dada por Scott para a linguagem e o discurso. Segundo Saffioti, linguagem, para Scott, é a arena básica para a construção do significado do conceito de gênero, o que estaria relacionado às referências pós-estruturalistas dessa autora. ${ }^{30}$ "Rejeitando determinações objetivas [Scott] assume o discurso como o demiurgo do real". ${ }^{31}$ Tal viés idealista não seria questionado por diferentes leitores de Scott no Brasil.

A reflexão crítica de Saffioti sobre Scott sugere (minha leitura) que as mulheres em movimentos sociais de corte de classe, ou seja, atentas aos conflitos de classe, tais como o MMTR movimento de mulheres rural $-^{32}$, ao usarem o texto de Scott, necessariamente procedem, mesmo que não o indiquem, a uma interpretação peculiar do que no texto dessa autora se considera "construção social da realidade". O MMTR no Rio Grande do Sul, por exemplo, reivindica um projeto político de classe, portanto, sua arena de luta não se restringe ao cenário de discursos, ao plano da linguagem, apoiando, em muitos planos, o Movimento dos Sem Terra (MST). ${ }^{33}$

Saffioti também critica o uso abstrato do conceito de poder no artigo citado de Scott, considerando-o uma armadilha relacionada à "concepção fluída de poder" de Foucault, autor de referência de Scott.

\footnotetext{
${ }^{29}$ MACHADO [1990] apud ARAÚJO, C. Marxismo, feminismo... Op. cit.

${ }^{30}$ Foucault e Derrida, apud SAFFIOTI, H. O estatuto teórico da violência de gênero. Op. cit.

${ }^{31}$ ID., IB., p.6.

${ }^{32}$ Estudado por THAYER, Millie. Feminismo transnacional... Op. cit., em Pernambuco, e por ABramovay, M. e CASTRO, M. G. Engendrando um novo feminismo... Op. cit., no Rio Grande do Sul.

${ }^{33}$ Abramovay, M. e CASTRO, M. G. Engendrando um novo feminismo... Op. cit.
} 
Mary Garcia Castro

Gênero e sua relação com poder tem sido reconsiderado de acordo com referências teóricas e ideológicas. Scott pode ter sido uma referência básica para algumas feministas, mas não para todas. Por outro lado, não foi uma das principais referências quando decola o debate sobre o conceito de gênero no Brasil.

\section{Articulações entre o feminismo de corte acadêmico e o de OBCs}

A inserção do debate sobre gênero nos sindicatos tem sido uma área de longo e bem sucedido investimento por um feminismo brasileiro com acento em classes sociais ${ }^{34}$, desde os últimos anos da década de 70, e vem se dando com a colaboração estreita de pesquisadoras feministas, algumas envolvidas em entidades feministas autônomas e outras em partidos políticos orientados para a esquerda (entre outras, a UBM - União Brasileira de Mulheres e a SOF - Sempre Viva Organização Feminista).

De fato, a produção de, e sobre, mulheres em sindicatos é um exemplo da interação bem sucedida entre feministas na academia, movimentos sociais e sindicatos. ${ }^{35}$

Um feminismo brasileiro sensível à classe tem mudado a cultura dos sindicatos, defendendo os direitos da mulher trabalhadora, crescentemente vulnerável nestes tempos neoliberais, especialmente se, além de trabalhadora, negra. ${ }^{36}$

${ }^{34}$ CASTRO, Mary Garcia. The Growth of Working-Class Feminism in Brazil. Nacla, vol. XXXII, n 4, January/February 1999, pp.28-31; e Gênero e poder no espaço sindical. Estudos Feministas, vol. 3, no 1, Rio de Janeiro, IFCS/UFRJ, 1995, pp.29-51; e MENICUCCI DE OlIVEIRA, E. A prática feminista e o gênero... Op. cit.

${ }^{35}$ Ver os trabalhos de Menicucci de Oliveira sobre saúde, gênero e trabalho e os de Araújo, sobre ação afirmativa, além das referências citadas.

${ }^{36}$ Em 8 de março de 1999, 3000 pessoas, a maioria mulheres, participaram na cidade de Salvador da marcha "Mulheres, agora outros 500: emprego, terra e cidadania", organizada pelo movimento de mulheres negras e mulheres de sindicatos. Entre as bandeiras básicas da marcha foram colocadas algumas das questões colocadas pelo feminismo brasileiro com assento na academia - 
Gênero e poder. Leituras transculturais

De fato, entre as várias características do feminismo no Brasil, sobressai uma ambígua, tensa, mas rica relação entre a academia e entidades do movimento social. Como observou Machado, há "uma tensão entre ativismo e conhecimento, mas não necessariamente destruição ou antagonismo". ${ }^{37}$ Machado também enfatiza que ambos tipos de práticas compartem certas perspectivas comuns, tais como a de cultivar a utopia e uma postura crítica. Compartem orientação contra desigualdades, diferenças hierárquicas e divisões sexuais do poder, do trabalho $e$ do direito ao prazer. ${ }^{38}$ Contudo, afiliações políticas, teóricas e ideológicas singularizam feminismos e a diversidade entre mulheres, assim como a diversidade entre feminismos na academia e em movimentos sociais e ONGs, e as diversidades de articulações entre tais territórios é um tópico emergente dos anos $90 .{ }^{39}$

cidadania, violência doméstica; crescimento de mortes maternas por falta de assistência médica. Segundo Olívia Santana, líder da UNEGRO - União dos Negros pela Igualdade -, em discurso pronunciado naquela marcha: "o Brasil tem uma das maiores taxas de mortalidade da América Latina, relacionada ao parto - cerca de 200 mortes de mulheres por 1000 crianças nascidas em 1997 e o governo brasileiro fez um corte de 2 bilhões de dólares no orçamento para educação e saúde, para atender a demanda do FMI, que orientou o saneamento das finanças do país". Os participantes também gritaram por trabalho; Olívia Santana denunciou que " $78 \%$ das mulheres trabalhadoras são oprimidas por baixos salários nos seus empregos no setor de serviços, especialmente no trabalho doméstico, um tipo de ocupação realizada por cerca de $90 \%$ de mulheres negras que ganham mensalmente um salário mínimo". Tais declarações foram reproduzidas nos principais jornais de Salvador. Os dados usados por Santana para denunciar os efeitos do neoliberalismo na vida das mulheres, especialmente mulheres negras trabalhadoras, são parte de estudos de feministas orgânicas, as que estão na academia e aquelas que têm colaborando com ativistas em várias organizações de bases populares - sindicatos, entidades do movimento Negro, entre outras.

${ }^{37}$ MACHADO, L. Z. Feminismo, academia e interdisciplinaridade... Op. cit.

${ }^{38}$ GIFFIN, K. Poder e prazer: Considerações sobre o Gênero... Op. cit.

${ }^{39}$ CASTRO, M. G. Engendrando poderes em tempos neo-liberais... Op. cit.; e BANDEIRA, L. e SIQUEIRA, D. A perspectiva feminista... Op. cit. 
O clássico debate dos anos 60 , sobre como tratar com classe e gênero, vem sendo renovado e resgatado pela via de reflexões sobre raça, geração e orientação sexual. Os movimentos sociais mais criativos e dinâmicos relacionados ao feminismo no Brasil tentam conjugar diferentes identidades, como os coletivos de mulheres negras, sugerindo um novo conhecimento sobre as interrelações entre gênero, geração, raça e classe.

Contudo, o estatuto do debate teórico sobre a combinação entre raça, racismo, geração, gênero e classe é ainda preliminar. Mulheres negras ativistas estão à frente, não apenas enfatizando desigualdades e problemas singulares, sobretudo nas áreas de saúde e educação, devido a práticas discriminatórias, mas também contribuindo para releituras da cosmologia religiosa afro-brasileira, uma ontologia alternativa sobre o papel da mulher e sobre a importância da comunidade e da ecologia. Sugere essa cosmologia também, crítica ao capitalismo, uma vez que valoriza a ecologia; a afetividade; o compartir, mas que o competir; valores de uso mais que os de troca, ou próprios à lógica de mercado, por exemplo. ${ }^{40}$

Outro conjunto de conhecimento feminista foi trazido nos anos 90 pelas feministas com experiência em teologia que enfatizam a espiritualidade, com base no catolicismo, mas implodindo-o pela defesa do aborto e uma reinterpretação da Bíblia e de outros textos canônicos do catolicismo. ${ }^{41}$

\footnotetext{
${ }^{40}$ Para as contribuições das feministas negras a uma epistemologia feminista afro-brasileira ver ROLAND, Edna. O movimento de mulheres negras; CARNEIRO, Sueli. Estratégias legais para promover a justiça social; SILVA BENTO, Maria Aparecida. Movimento sindical e o Estado; In: GUIMARÃES and HunTLEY. Tirando a máscara. Ensaios sobre o racismo no Brasil. São Paulo, Paz e Terra, 2000; RIBEIRO, Matilde. Mulheres negras brasileiras: de Bertioga a Beijing; SIQUEIRA, Lourdes. Iyámi, Iyá, Agbás: dinâmica da espiritualidade feminina em templos afro-baianos; BAIRROS, Luiza. Nossos feminismos revisitados. Estudos Feministas, vol. 3, n 2, IFCS/UFRJ, 1995.

${ }^{41}$ Ver, por exemplo, RosADO, Maria José F. De mulheres e de deuses. Estudos Feministas, nº 0, 1992, pp.5-30.
} 
Gênero e poder. Leituras transculturais

Tais práticas de conhecimento e ativismo, que re-visitam criticamente cosmovisões, religiões e espiritualidade também pouco teriam que aprender de textos que circulam por categorias convencionais como o de Scott. ${ }^{42}$

\section{"Empoderamento" de gênero - leituras transculturais por mulheres em Organizações de Base Comunitária (OBCs)}

Thayer faz referência às negociações entre um movimento social de mulheres rurais do Nordeste do Brasil - MMTR - e uma organização feminista por ela caracteriza como "ONG dirigida por feministas de classe média urbana" - o SOS Corpo. Argüindo, segundo minha interpretação, que o MMTR, de certo modo, tornou-se transnacional através dessa colaboração e que o SOS Corpo traduziu o conceito de gênero para o movimento popular, introduzindo a tradução do artigo de Joan Scott. ${ }^{43}$ Ela observa que o conceito de gênero foi atraente para o MMTR, porque:

Como o MMTR tinha ligação com um movimento com membros de ambos os sexos, mudar o discurso tinha implicações políticas, abrindo oportunidades para discussões entre homens e mulheres o que não era possível quando o sujeito era limitado à "mulher". Finalmente, mais

\footnotetext{
${ }^{42}$ ScotT, J. W. Gender: A Useful Category... Op. cit.

43 "Além das negociações com ONGs, como o SOS Corpo, sobre as condições de acesso a sua base popular, o MMTR estabeleceu uma relação direta com discursos feministas transnacionais divulgados no nordeste, tanto por agências de desenvolvimento quanto por instituições feministas profissionalizadas. Um dos exemplos mais claros desse processo foi a resposta do MMTR ao discurso de gênero apresentado aos movimentos de mulheres de Pernambuco em 1990. Naquele ano, uma participante do SOS Corpo leu o artigo "Gênero: uma categoria útil para análise histórica" [1991] de Joan Scott e a ONG o traduziu e começou a promover discussões sobre esse novo conceito dentro do movimento feminista local. Em poucos anos, o SOS e alguns outros grupos ofereciam oficinas sobre relações de gênero para movimentos populares, instituições não governamentais, instâncias do Estado e outras instituições”. THAYER, Millie. Feminismo transnacional... Op. cit., p.123.
} 
Mary Garcia Castro

para o fim da década, o crescente interesse das agências de desenvolvimento em ver a nova terminologia integrada às propostas de financiamento foi um incentivo a mais para novas incursões no "gênero". 44

Thayer reconhece que o MMTR desenvolveu releitura própria do conceito de gênero, dando ênfase ao vetor igualdade entre os sexos. "Desse modo o MMTR se apropriou de um recurso transnacional e o reconstruiu para ajudar suas participantes a encarar seus próprios desafios políticos locais". ${ }^{45}$

Concordo com as inferências básicas de Thayer $^{46}$ sobre a reapropriação do conceito de gênero pelos movimentos sociais, tendo em vista não apenas suas vidas e necessidades materiais, mas também, acrescento, seus projetos coletivos. Contudo, parece-me simplista a conclusão de que tal reapropriação do conceito de gênero por uma entidade de base popular seria orientada por fins instrumentais imediatos, ou seja, pela potencialidade do conceito de gênero apelar para igualdade nas relações entre homens e mulheres da mesma classe social. Inúmeros tipos de traduções e reapropriações são possíveis. Partindo de outras referências empíricas ${ }^{47}$, argumento que várias ativistas em $\mathrm{OBCs}$, especialmente as participantes em organizações mistas, adotam o conceito de gênero, mas não apenas por razões instrumentais, para agradar aos homens ou pelo fato de que um projeto recorrente ao conceito de gênero estar mais habilitado ao patrocínio de agencias internacionais.

Mulheres em assentamentos rurais, por exemplo, acentuam a importância de combinar uma agenda relacionada a demandas

${ }^{44}$ ID., IB., p.124.

${ }^{45}$ THAYER, Millie. Feminismo transnacional... Op. cit., p.125.

${ }^{46}$ ID., IB.

${ }^{47}$ Abramovay, M. e Castro, M. G. Engendrando um novo feminismo... Op. cit.; e RuA, Maria das Graças e ABRAmovaY, Miriam. Companheiras de luta ou "coordenadoras de panelas". As Relaçóes de Gênero nos Assentamentos Rurais. Brasília, UNESCO, 2001. 
Gênero e poder. Leituras transculturais

de classe com outras sobre direitos sexuais e reprodutivos das mulheres e relatam casos de argumentação critica com agências de financiamento. ${ }^{48}$

De fato, de acordo com a pesquisa desenvolvida em $1998^{49}$, em diferentes áreas do Brasil, com mulheres em posição de liderança em OBCs, como se ilustra a seguir, o conceito de gênero favoreceria um melhor diálogo com companheiros homens, permitindo foco sobre condições materiais, levando em conta serviços fornecidos pelo Estado; assim como criando um foco sobre relações sociais entre homens e mulheres em diferentes áreas, que poderiam, segundo entrevistadas, mudar através da reeducação ou transformação dos homens ou com uma perspectiva menos antagônica com os homens. Mas esses são apenas alguns dos diversos usos do conceito de gênero em OBCs.

Diferentemente do uso acadêmico corrente do conceito de "empoderamento" de gênero, em organizações de base, de classe ou comunitária, entre ativistas de $\mathrm{OBCs}$, tal termo seria comumente traduzido como impulso para a admissão necessária de mulheres em posições de poder, em posições de direção em distintas instituições, porém, a maioria das entrevistadas sugeriram que "vir a ter poder" - forma como muitas bem se referem ao neologismo "empoderamento" - é um processo aberto, e insistiam que para tanto seria preciso ter igual acesso a recursos para tratar dos problemas comunitários, e muitos outros "negados pelo Estado" e para ganhar voz nos espaços públicos e na família expressões entre aspas, das entrevistas de Abramovay e Castro. ${ }^{50}$

Muitas das entrevistadas não se declararam feministas $e$ eram críticas do conceito de gênero, considerando a ligação do

\footnotetext{
${ }^{48}$ ID., IB.

${ }^{49}$ Abramovay, M. e CAStro, M. G. Engendrando um novo feminismo... Op. cit.

${ }^{50} \mathrm{Em}$ 1998, desenvolvemos pesquisa patrocinada pela UNESCO, entrevistando 70 mulheres em posições de liderança em diferentes agências de organizações de base, em diferentes regiões do Brasil - algumas mencionadas na nota que segue. Ver ID., IB.
} 
conceito a um "feminismo de influência norte-americana" e à "predominância de mulheres da classe média em organizações feministas que recorrem ao conceito". Mas muitas consideravam gênero $e$ as perspectivas feministas importantes para seu trabalho e por diferentes tipos de raciocínio, como se ilustra a seguir.

\section{Mapeando vozes sobre gênero e "empoderamento" 11}

Diversos e complexos significados surgiram dos testemunhos das mulheres que entrevistamos (ver nota 51), muitas cujo enfrentamento com a pobreza é uma realidade cotidiana.

A maioria das mulheres líderes de base consideraram que o conceito de gênero no movimento das mulheres tem gerado avanços na discussão de problemas e programas nas relações homem-mulher, não apenas na área dos direitos das mulheres.

\footnotetext{
${ }^{51}$ Para este artigo recorremos a testemunhos de mulheres em algumas das organizações pesquisadas por ABRAMOVAY, M. e CASTRO, M. G. Engendrando um novo feminismo... Op. cit., a saber: 1) ONGs de formato advocacional, mais orientadas para raça, para defesa da população indígena (ANAI - Salvador) e para defesa da população negra (UNEGRO - Salvador); 2) movimentos sociais contra privilégios econômicos - para defesa das pessoas sem-terra (MMTR e MST - no interior do Rio Grande do Sul e do Paraná); 3) ONG de caráter advocacional e para programas para defesa dos direitos de gênero das lésbicas (GLB - Salvador); 4) ONG no campo da educação para crianças e adolescentes na rua ou em famílias pobres - Projeto AXÉ e ONG CRIA, Salvador; 5) ONG com programa orientado para a área do treinamento ocupacional e cidadania racial/cultural, que trabalha com adolescentes negros pobres, em Salvador Projeto Profissionalização para a Cidadania; 6) Sindicatos e associações de trabalhadores relacionados à Confederação Nacional de Trabalhadores Rurais, Brasília; à União de Associações de Comunidades, Canguaçu, Rio Grande do Sul e à Associação dos Trabalhadores com Babaçu, Maranhão; 7) ONGs locais da área de ecologia - Reflorar Gamba e Centro Educacional Ambiental Parque São Bartolomeu, Bahia; 8) Sindicato de Trabalhadoras Domésticas - Sindoméstico, Salvador; 9) Associação de Escolas Comunitárias - CECUP, Salvador; 10) Associação de Moradores de Bairros Pobres - Bairro da Paz e Grupo de Mulheres do Calafate, Salvador; Associação de Bairros em Amargosa, nessa cidade na Bahia e a Federação das Associações de Moradores - FABS, Salvador.
} 
Gênero e poder. Leituras transculturais

Mas, cada 3 em 12 entrevistadas expressaram algum desconforto com o uso pragmático do conceito.

Para algumas, o conceito era percebido como "divisionista", gerando relações antagônicas entre homens e mulheres - ou seja, com um sentido bem distinto ao registrado por Thayer. ${ }^{52}$ Para outras, ainda se acentuaria com o conceito a condição da mulher, oferecendo pouco no trabalho para mudanças em valores e nos comportamentos dos homens. Outra posição emblemática seria considerar que com "o conceito de gênero, não há mulher, perdendo-se o ponto de referência para a mobilização" (líder no MST). Mas a maioria considerou o conceito útil na luta contra estereótipos sobre as mulheres.

Muitas das organizações (ver nota 51) conheciam os "manuais" sobre gênero fornecidos por agências internacionais, mas não os seguiam necessariamente.

Algumas entrevistadas tornaram-se familiarizadas com o conceito de gênero através de contatos com organizações feministas autônomas e textos publicados nos meios de comunicação feministas mais amplamente accessíveis. ${ }^{53}$ Algumas, de fato, mencionaram ter lido o artigo traduzido de Joan Scott (versão publicada em 1990), mas a maioria destacou entre suas leituras, autoras nacionais como Saffioti, Souza Lobo, Castro e Heilborn. ${ }^{54}$ Um livro sobre gênero - Uma questão de gênero ${ }^{55}$-, bem como as revistas feministas - Cadernos Pagu e Estudos Feministas - foram também amplamente mencionadas.

\footnotetext{
52 THAYER, M. Feminismo transnacional... Op. cit.

${ }^{53}$ Tais como a revista Presença da Mulher, publicada pela UBM e os Boletins das ONGs CFEMEA e SOF.

${ }^{54}$ No caso das duas últimas, referências comuns foram artigos publicados em livro editado pela UNICEF e o Instituto Brasileiro de Administração Municipal no início dos anos 90, distribuídos gratuita e amplamente.

55 Oliveira Costa, A. e Bruschini, C. Uma questão de gênero. Op. cit.
} 
Em outras palavras, o destacado por Thayer $^{56}$, quanto a importância de Scott como leitura sobre gênero para o MMTR de Pernambuco, não procede para o caso de outras $\mathrm{OBCs}$ como as que aqui citamos (ver nota 51).

Algumas poucas entrevistadas, que destacaram leituras de autores não brasileiros, mencionaram o texto de Molyneaux sobre gênero como interesse estratégico e pragmático. ${ }^{57}$ Uma ativista do MST citou o artigo de Isabel Larguia sobre sexo e classe, que também foi difundido no Brasil ao final dos anos 80, como sendo muito usado por sua organização em discussões sobre gênero.

As seguintes posições surgiram das entrevistas sobre o mais importante do conceito de gênero (adaptei, combinando falas, mas conservando termos e idéias):

i. Ênfase na relação entre o emocional e o biológico, tendo o corpo como uma importante referência na discussão das necessidades, singularidades e direitos das mulheres;

ii. Chamada para a necessidade de identificar diferenças entre homens e mulheres sem recorrer a categorizações hierárquicas;

iii. Colaborar para denunciar vários tipos de violências, estereótipos e discriminações sofridas pelas mulheres;

iv. Ser usado para indicar-se divisões sexuais do trabalho $e$ poder nas esferas pública e privada e a falta de reconhecimento do valor social do trabalho das mulheres no mercado e nas esferas domésticas;

v. Ser útil para se destacar a opressão social que os homens pobres experimentam;

vi. Sugerir a importância da unidade familiar como um domínio afetivo onde as mulheres cuidam das crianças e dos companheiros homens;

\footnotetext{
${ }^{56}$ THAYER, Millie. Feminismo transnacional... Op. cit.

${ }^{57}$ Versão em xerox que circulou no Brasil ao final dos anos 80 .
} 
Gênero e poder. Leituras transculturais

vii. Permitir enfatizar a necessidade de se investir em uma nova sociedade baseada na amizade e igualdade entre homens e mulheres.

Sobre gênero e poder, a maiorias das mulheres líderes não consideraram marcas de gênero como obstáculo em seu trabalho de ativistas, quanto ao reconhecimento social, mas se enfatizou a carga de trabalho que têm que suportar, negociando estar a cargo de inúmeros tipos de trabalho. Algumas indicaram que ao transitar por diversas agências - governo, organizações internacionais, sindicatos e partidos políticos - adquiriram uma consciência das especificidades baseadas em gênero, algumas das quais são detalhadas a seguir tendo em vista suas próprias palavras ou idéias expressas nas entrevistas:

i. Nas esferas públicas, "homens com autoridade são, muitas vezes, paternalistas ou encontram outras formas de sutilmente afirmarem seu poder no trato com as mulheres";

ii. A sedução é estratégia de dupla via, "usada tanto por funcionários de agências financiadoras, como por mulheres em organizações pretendentes de financiamentos";

iii. Para as mulheres em atividades de nível mais popular, muitas vezes, é "mais difícil negociar autoridade como mulheres líderes do que no caso de homens em liderança, mesmo que da mesma organização";

iv. "Os homens nas agências de financiamento de projetos comumente não levam em conta o conhecimento de base popular, ou o conhecimento prático das mulheres, por exemplo em assuntos como o turismo sexual ou a violência doméstica". "Em agências de financiamento, muitos funcionários são economistas neoclássicos, mas se posicionam como 'expertos' das relações sociais cotidianas e das experiências da vida diária";

v. "No exercício do poder em agências governamentais ou de financiamento, os homens se consideram os 'donos 
Mary Garcia Castro

da verdade' quando negociam com mulheres de organizações que solicitam fundos. Mas temos o poder da argumentação e do conhecimento sobre recursos, o que pode contar a favor nas negociações".

Em resumo, as relações entre poder e gênero são comumente relacionadas a diferentes sistemas de privilégios e a crítica aos homens é mais comum, quando o foco são relações no domínio do público.

A maioria das entrevistadas adotava posição crítica a respeito da expressão "empoderamento", associada a um tipo de política de identidade, que se restringiria a necessidades e áreas específicas. Seria pensado como um conceito "conservador", uma "moda importada" pelo qual se tenderia a minimizar ou ignorar críticas a autoritarismos e a arrogância em sistemas de poder, presente especialmente na esfera governamental, porém, segundo várias líderes, estariam também presentes nas "negociações com aqueles no poder, tais como os representantes oficiais das agências de financiamento", assim como "nas relações com os companheiros de organização".

Todas as entrevistadas consideraram que é importante para as mulheres ter posições de mando no governo $e$ nas instituições formais, mas acrescentavam um "porém", relacionado à questão da representação: "depende da mulher"; "depende da sua classe"; "depende da raça"; ou "depende do compromisso social".

Muitas frisaram que a liderança e a representação exercida pelas mulheres pobres seria mais efetiva se houvesse mais acesso à educação e ao treinamento, também em sindicatos e partidos políticos. Considerou-se também que deveria haver igual acesso por homens e mulheres aos recursos das organizações. Uma entrevistada frisou que, a despeito do sistema de quotas empregado pelos partidos progressistas, requerendo ao menos $30 \%$ de candidatas mulheres, essas não recebiam o mesmo apoio organizacional ou partidário, como seus contrapartes masculinos. 
Gênero e poder. Leituras transculturais

Muitas foram críticas quanto à falta de representação pelas mulheres negras no poder legislativo nacional e quanto à tendência de ser citada a presença de Benedita da Silva, a única mulher negra senadora, como evidência de que haveria democracia racial e de gênero no Brasil - "a nossa negra de plantão".

A maioria das mulheres das OBCs também defendeu que o movimento de mulheres no Brasil deveria articular um fórum para discussão sobre o projeto político para o Brasil e os tipos de poder que as mulheres desejam. Nessa linha, houve uma crítica freqüente ao que é chamado de "feminismo institucionalizado" (uma expressão também presente no trabalho de campo), considerado um feminismo eficiente na defesa das leis $e$ programas específicos para os direitos das mulheres, mas ausente na discussão crítica do neoliberalismo e da injustiça social. O "feminismo oficial" - outra expressão do campo, referindo-se à parceria direta das feministas com o governo federal - também recebeu algumas críticas e defesas.

Algumas entrevistadas enfatizaram que o ponto crucial não seria conseguir posição de poder de decisão, mas ter estratégias para promover mudanças culturais, especialmente na "cultura da intolerância que é parte da identidade brasileira". (militante da UNEGRO.)

Algumas declararam que se sentiriam melhor representadas por um homem de um partido progressista do que por uma mulher de um partido conservador.

Outras enfatizaram que tanto o homem quanto a mulher não estariam imunes à sedução do poder $e$ sua tendência para a corrupção, mas que tais possibilidades seriam minimizadas por homens $e$ mulheres, se as necessidades dos pobres fossem consideradas como prioridades. Em outra linha, vários depoimentos que se declarariam favoráveis a mulheres em posições de poder, para 
Mary Garcia Castro

mudar a qualidade do poder [e porque] uma mulher em posição de poder transmite um peso simbólico, especialmente para a geração mais jovem. (líder de associação de bairro em Salvador.)

Outro tema "divisionista" é a idéia (ou ideologia) de que as mulheres são mais sensíveis para questões sociais relacionadas à qualidade da vida cotidiana. Enquanto algumas discordam, outras sentem que as mulheres são mais sensíveis a questões da comunidade e da família, especialmente em razão de seus papéis como mães e de tarefas familiares ou, como algumas entrevistadas do movimento lésbico-feminista colocaram, "as mulheres heterosexuais podem ser mais sensiveis às necessidades das mulheres lésbicas do que os homens". Mas era comum a ressalva de que as mulheres pobres estariam melhor representadas por outra mulher, se fosse essa também uma mulher pobre.

Em resumo, as diversidades de leituras sobre e através de gênero e poder, quando se focaliza OBCs, também é a norma, como o destacado para o caso de feministas na academia.

\section{Gênero, poder e conhecimentos feministas - leituras transculturais}

Uma visão simplificada sobre gênero e poder não dá conta da complexidade das relações entre teoria e prática, tensão que se irradia por todos os campos que dizem respeito às relações sociais. Por outro lado, as tensões entre tipos de conhecimentos se manifestam também em termos da equação entre o horizonte temporal e os tipos de objetivos (tais como aqueles mais relacionados a ações imediatas, para intervenção; $e$ aqueles planejados para o longo prazo, para compreensão crítica $e$ mudanças). Tais complicadores se infiltram nas relações entre movimentos sociais e conhecimento acadêmico, assim como no feminismo como cultura escrita e no organizado para ações. Mas, acima de tudo, "encontros" e "desencontros" estão relacionados a uma disputa de significados, tais como os que se dão, ainda que 
Gênero e poder. Leituras transculturais

não necessariamente assumidos, entre feminismos socialista e pósestruturalista. Por outro lado, agendas pessoais e políticas também jogam um papel, uma vez que o poder é assentado em interesses individuais e a competição é uma marca do mercado no campo acadêmico.

De todo modo, enfatizaria que uma característica do conhecimento feminista brasileiro em geral é que as tensões entre o conhecimento acadêmico e o ativista, nos anos 90, têm-se desenvolvido de maneira produtiva, com ganhos relativos para inúmeras esferas da construção feminista. ${ }^{58}$

Em agosto de 2000, uma das mais impressionantes marchas contra a política neo-liberal, organizada por trabalhadores rurais, teve lugar em Brasília. Mais de 2000 mulheres (apenas mulheres) ganharam a rua no que ficou conhecido como "Marcha das Margaridas". Do documento distribuído pela marcha extraímos:

Nós temos 2000 razões para marchar contra a fome, a pobreza e a violência sexista, porque entre os pobres, nós somos as mais pobres e passamos necessidades de coisas básicas. De 1964 até 1996, daqueles que foram beneficiados pela reforma agrária, apenas $12,6 \%$ eram mulheres. Daqueles que foram beneficiados pelo Programa Nacional de Apoio Familiar (PRONAF), de caráter rural, apenas 7\% eram mulheres. Cerca de $81 \%$ de trabalhadores rurais são do sexo feminino e não tiveram nenhum rendimento em 1998. A falta de investimento governamental em políticas públicas aumenta a exploração da classe trabalhadora $e$, especialmente das mulheres trabalhadoras rurais. A falta de acesso à terra, a recursos naturais e produtivos, a direitos sociais e do trabalho não permitem a realização de um desenvolvimento sustentável. ${ }^{59}$

${ }^{58}$ MACHADO, Lia Zanotta. Estudos de gênero: para além do Jogo entre intelectuais e feministas. In: SCHPUN, Monica Raísa. Gênero sem fronteiras. Florianópolis, Editora das Mulheres, 1997.

${ }^{59}$ Folheto assinado por inúmeras organizações baseadas em classe - CONTAG; FETAGs; STRs; CUT; MMTR/NE*; MNQC; CNS; MLT; UBM; SOF; TIJUPÁ; 
Gênero e classe não são apenas posições, mas projetos políticos, e como tal estão entrelaçados, como na declaração anterior, e sugerem que mais do que serem registrado como construções sociais, valeria cuidar do acento em modelos de sistema e seu perfil histórico.

Das entrevistas e análises das experiências de diferentes casos selecionados em Abramovay e Castro ${ }^{60}$, considero que as mulheres em organizações de base comunitária e em movimentos sociais populares no Brasil podem ver a relação entre mulheres, gênero e poder diferentemente das mulheres no feminismo transnacional mais visível ou legitimizado, que comumente insistiriam sobre o poder como inclusão no sistema de decisão, ou por uma representação por quota, nos programas de ação afirmativa e leis. Também ressalto como as mulheres pobres, em organizações de base comunitária, bem como as envolvidas em movimentos relacionados a pessoas pobres, tais como o Movimento Negro, transbordariam as políticas de identidade, combinando perspectivas econômica, cultural, macro $e$ microscópica.

Mais que considerada como uma posição individual, um assento no sistema de poder oficial, "empoderamento" é traduzido como relacionado à necessidade de ação em diferentes níveis, como um processo dependente das práticas, tais como:

1) Ao nível de organizações de bases comunitárias, através do fortalecimento de agências e tecedura da solidariedade, bem como por aumentar o acesso ao capital simbólico - como educação e informação - que deveria ser socializado;

2) Ao nível da formação do sujeito, por investimento em auto estima - não necessariamente no plano individual, orientado

FASE e ESPLAR. In: RuA, M. G. e ABRAmovay, M. Companheiras de luta... Op. cit., p.17. *A organização de mulheres rurais é mencionada em THAYER, Millie. Feminismo transnacional... Op. cit..

${ }^{60}$ Abramovay, M. e Castro, M. G. Engendrando um novo feminismo... Op. cit., ver nota 51. 
Gênero e poder. Leituras transculturais

para a mobilidade social, porém mais na redescoberta de uma história coletiva negada - uma busca por identidade coletiva;

3) Ao nível das restrições materiais específicas, poder significaria ter acesso a direitos para o exercício da cidadania. $\mathrm{O}$ processo de formação de identidade começa de formas muito concretas e, muitas vezes, nada tem a ver com debates sofisticados dos intelectuais pós-modernos sobre identidade.

Ter uma identidade é ser poderosa. Para mulheres trabalhadoras rurais, aqui, ter uma identidade é começar com ter acesso a coisas como: certidão de nascimento, título de eleitor, carteira de trabalho e carteira sindical. Quando seus maridos morrem, comumente, as mulheres tem negada a titularidade do acesso à terra, porque elas não têm uma identidade - carteira de identidade, documentos provando que ela era casada, que ela era também co-proprietária da terra. E sem esses documentos, ela também não pode ter acesso aos benefícios de seguro social $e$ aposentadoria do governo. ${ }^{61}$

Avanço a sugestão de que o "empoderamento" seria mais do que algo "dado por" ou "fixado em", mas que usualmente toma a forma de um processo, uma conquista almejada $e$ comumente considerada como "um meio para ter voz", tal poder seria um meio para ter poder, mais do que um objetivo único.

A transnacionalidade do feminismo e do movimento de mulheres em OBCs dar-se-ia não somente pela absorção de leituras de fora. Mesmo mulheres em comunidades rurais remotas estariam, de certa forma, ligadas ao mundo das idéias feministas internacionais; já seriam transnacionais há muito tempo e por diversas formas. A maioria das entrevistadas conhecia a Plataforma de Ação acordada em Beijing 1995, algumas já tinham participado de fóruns internacionais e mantinham contacto com ativistas e redes no exterior, ainda que a maioria não tivesse acesso à internet. $\mathrm{O}$ conceito de gênero lhes era familiar.

${ }^{61}$ D. Lilite - líder do Sindicato dos Trabalhadores Rurais em Amargosa, Bahia. In: ABRAmovay, M. e CASTRO, M. G. Engendrando um novo feminismo... Op. cit. 
A tese é de que uma rede transnacional pode também envolver idéias, conceitos e projetos gerais compartidos - tais como o dos direitos das mulheres - mesmo quando esses projetos ou idéias entram em conflito com parceiros/as ou "iguais". Não é por acaso que a diversidade de feminismos é tão mais saliente hoje. Todavia, tal diversidade na linguagem das mulheres em movimentos de organizações de base e populares está enraizada em uma localização com perfis próprios. ${ }^{62}$

A localização - o país das exclusões - não está necessariamente presente quando o feminismo flutua nos escritos acadêmicos, encontros e seminários internacionais ou nas telecomunicações. A localização tem que ser ressaltada quando se constrói a rede transnacional. Por outro lado, referências "prémodernas" e "modernas" estão conectadas com um certo hibridismo, nos discursos das entrevistadas (ver nota 51). Oposições binárias são comumente usadas, como mencionado, mas não necessariamente como avenidas únicas, "não como pontos fixos". ${ }^{63}$

Não há uma narrativa única, mesmo em termos de exposição de projetos. "Empoderamento" e gênero são retraduzidos em "histórias fragmentadas" em um processo de busca por "identidades que fluam com alguma [aparente] coerência" ${ }^{64}$

\footnotetext{
${ }^{62}$ O XII Encontro de Mulheres Brasileiras (Salvador, 1997) chamou-se "Gênero com Diversidade, no País das Exclusões".

${ }^{63}$ CORONIL. Introdução. Op. cit.

${ }^{64}$ Expressões tomadas de CoRONIL. Introdução. Op. cit.
} 